\title{
Development and content validity of the Brazilian Brief Neuropsychological Assessment Battery Neupsilin
}

\author{
Rochele Paz Fonseca ${ }^{1}$, Jerusa Fumagalli de Salles ${ }^{2}$ and Maria Alice de Mattos Pimenta Parente ${ }^{2}$ \\ 1 Pontifícia Universidade Católica do Rio Grande do Sul, Brazil \\ 2 Universidade Federal do Rio Grande do Sul, Brazil
}

\begin{abstract}
This paper aims to present the process of construction and content validity of the Brazilian Brief Neuropsychological Assessment Battery Neupsilin, developed to briefly examine the neuropsychological profile of both clinical and healthy populations. It evaluates time and spatial orientation, attention, perception, memory, arithmetic abilities, language, praxia and executive functions (problem solving and verbal fluency). The process of construction was based on psychometric procedures: 1) construction of a preliminary version of the instrument, founded on clinical and research experience of the three specialists, as well as on research on the literature and on already available instruments; 2) blind judges' analyses: a) an analysis of the importance of the inclusion of each subtest considering the assessed construct and the instrument's goal, b) an analysis of the adequacy of each item regarding the construct; 3) reformulation of the instrument; 4) semantic analysis of the items and brainstorming; 5) final analysis done by three specialist judges; 6) pilot study and final version, and 7) content validity. Modifications were done in each stage of the development of the Neupsilin. It demonstrated adequate content validity, with advantages and limitations. Keywords: neuropsychological assessment, test development, content validity, cognition.
\end{abstract}

Received 11 June 2008; received in revised form 30 June 2008; accepted 30 June 2008. Available online 30 June 2008

\section{Introduction}

In Brazil, there is an important demand for neuropsychological assessment instruments adapted to the social, cultural and linguistic features of its population. Neuropsychological evaluation can be done through a flexible exploration (non-standardized tasks and standardized subtests), and/or through a fixed assessing battery (standardized instruments). For the adjustment

Rochele Paz Fonseca, Ph.D. is an Adjoined Professor of the Psychology Faculty and of the Post-Graduation Program in Psychology, Human Cognition area, at Pontifícia Universidade Católica do Rio Grande do Sul - PUCRS. Coordinator of the Research Group "Neuropsicologia Clínica e Experimental" (GNCE), Brazil. Jerusa Fumagalli de Salles, Ph.D. is an Adjoined Professor of the Institute of Psychology, Department of Developmental and Personality Psychology and PostGraduation Program in Psychology at Universidade Federal do Rio Grande do Sul - UFRGS, coordinator of the "Núcleo de Estudos em Neuropsicologia Cognitiva" (Neurocog), Brazil. Maria Alice de Mattos Pimenta Parente, $\mathrm{PhD}$ is an Adjoined Professor of the Institute of Psychology, Department of Developmental and Personality Psychology, and PostGraduation Program in Psychology at Universidade Federal do Rio Grande do Sul - UFRGS, coordinator of the lab "Laboratório de Neuropsicolingüística" (Neupsilin), Brazil. Corresponding regarding this article should be addressed to Rochele Paz Fonseca, Avenida Ipiranga, 6681, prédio 11, sala 938. CEP: 90619-900, Porto Alegre/RS. Brazil. Phone / Fax: +55 51 33203500 ext. 7745. E-mail: rochele.fonseca@pucrs.br of a neuropsychological assessment instrument to the characteristics of the population of a determined country, during the development and/or adaptation process, it is fundamental to consider the interface between postulations brought by neuropsychology (Lezak, Howieson, \& Loring, 2004; Strauss, Sherman, \& Spreen, 2006), experimental psychology, cognitive psychology (Posner, 1998), psycholinguistics (Gernsbacher, 1994; Harley, 2001) and psychometrics (Pasquali, 2003; Urbina, 2004).

The theoretic-methodological postulations from neuropsychology involve the concept of modularity, that is, it assumes that the cognitive system contains subsystem components, or cognitive processors of relative independence. These subsystems have to be considered in the constructs included in the assessment process. They also encompass the notion of double and simple dissociation (Willmes, 1998). One of the aims of neuropsychological assessment is to find dissociations between functions and their components, that is, preserved and impaired abilities. Along with neuropsychological criteria, psycholinguistic criteria must be considered in the elaboration of items, which compose evaluations with linguistic stimuli of different levels of complexity (words, non-words, sentences, texts). At the word level, aspects to be considered are familiarity, frequency in the language, lexical extension, prototypicality, concreteness, lexicality, regularity, phonologic or semantic relationships, grammatical class, among other psycholinguistic factors. At the sentence level, some variables are essentiality, contextuality, plausibility, 
syntactic extension, conventionality, directionality and literality. In terms of discourse, aspects generally considered are cohesion, coherence and textual extension (Brookshire, 2003; Reis \& Castro-Caldas, 1997; Parente \& Salles, 2007; Salles \& Parente, 2002, 2007).

Regarding psychometric criteria, instruments can be constructed based on theoretical and empirical procedures suggested in Pasquali's (1999) fluxogram, including the attainment of normative data (in general by age and education), reliability and validity (Capitani, 1997; Geisinger, 1994, 1998; Guillevic \& Vautier, 2005; Pasquali, 2003; Urbina, 2004). Thus, it can be observed that, besides the interest in cognitive functioning, the product psychometric quality of fixed battery scores - is also being focused by neuropsychological assessment studies. Finally, the focus of experimental neuropsychology contributes to the methodological reasoning of considering criteria for experimental manipulation of variables which potentially interfere with performance in each task. It is necessary to know experimental paradigms, that is, standardized strategies for the study of the distinct cognitive processes (Sevilla, 1997).

Neupsilin was, therefore, developed based on such pillars, and its construction (and not the adaptation of any already existing international instrument) justifies itself for a series of factors. Firstly, the need of an instrument constructed with standardization for the Brazilian population. It is noticeable that in Latin America, traditionally, tests developed in other countries have been translated and used based on international performance norms, obtained for foreign populations (Ostrosky-Solís, Ardila, \& Rosselli, 1999). This practice may invalidate results found in the neuropsychological assessment process. Secondly, there is a need for a brief neuropsychological assessment instrument to be used in clinical, hospital and research context. There is a lack of tests, even in the world context, which do not demand an extended time of application (Ostrosky-Solís et al., 1999). Considering the Brazilian literature in the field, we have not found studies with brief instruments whose purpose is to provide a general profile of neuropsychological functions. Some of the assessment instruments used in Brazil, such as the Mini Mental State Examination (MiniMental) (Almeida, 1998; Bertolucci, Brucki, Campacci, \& Juliano, 1994; Camozzato \& Chaves, 2002; Chaves \& Izquierdo, 1992; Folstein, Folstein, \& McHugh, 1975), the Criteria of Positivity for Cognitive Deficits (Chaves \& Izquierdo, 1992); the Frontal Assessment Battery (FAB Battery) (Beato, Nitrini, Formigoni, \& Caramelli, 2007), and the Working Memory Battery - BAMT-UFMG (Wood et. al., 2001) focus on the assessment of one or few neuropsychological functions, requiring the clinician/ researcher to adopt a set of combined tasks to build up a neuropsychological profile.

More specifically, Neupsilin presents some tasks which are similar to those of the MT-86b Protocol - Protocole Montréal-Toulouse d'examen linguistique de l'aphasie MT-86 (Nespoulous, Joanette, \& Lecours, 1986), such as those of written and oral comprehension. It also shares some similar tasks with the Mini-Mental (Folstein et al, 1975), such as time and spatial orientation tasks, repetition of digit sequences and sentence writing. Similar to the Rey Auditory Verbal Learning Test - research version (Rey, 1958), it presents word lists for free, immediate and delayed recall, besides recognition. However, due to the fact that it is a brief instrument, there is no list repetition (learning curve assessment). Compared to the Working Memory Battery - BAMT-UFMG (Wood et. al., 2001), which presents a listening comprehension attainment task, Neupsilin offers a listening span task of words in sentences. In the same way as the Boston Naming Test (Kaplan et al., 1983, cited by Strauss et al, 2006), it approaches picture naming, but it also includes real objects. Similar to the phonemic verbal fluency task entitled FAS (Strauss, Sherman \& Spreen, 2006), it also presents a verbal fluency task (words beginning only with the letter F).

Neupsilin's advantage in the comparison with other instruments adopted in Brazil is the fact that it is a brief battery which encompasses the evaluation of all neuropsychological functions in a single instrument. It is characterized, therefore, for reaching a wider scope than a screening instrument does, as well as for not being so specific, as the Mini-Mental is, known for its role in detecting dementia or cognitive decline. Thus, Neupsilin is able to offer a brief neuropsychological profile of varying clinical populations whose sensitivity and clinical norms must be investigated in each clinical group and subgroup, for instance, of closed head injury, cerebellar lesions, frontal lesions, tumors, depression, and schizophrenia, among others.

The present study aims to present the process of development and assessment of content validity of the Brazilian Brief Neuropsychological Assessment Battery Neupsilin considering the factors: 1) relevance of the lack of suitable neuropsychological performance norms for the Brazilian population, 2) need for a brief instrument which would allow the investigation of an initial neuropsychological profile, 3) and the great necessity for specific neuropsychological assessment instruments to be applied to brain-damaged and nondamaged individuals, which simultaneously consider neuropsychological, experimental, psycholinguistic, and psychometric knowledge. The test aims to provide a brief neuropsychological qualitative and quantitative profile through the identification of impaired and preserved functions of the following processes: time and spatial orientation, attention, perception, memory, arithmetic abilities, language, motor abilities, executive functions (problem solving and verbal fluency).

\section{Methods}

\section{Participants}

Forty individuals participated in this study, considering all the phases described in the procedures. These included 12 judges, with research expertise in neuropsychology and/or psychological assessment, 12 students members of research groups in neuropsychology (phase 4) and 16 adults evaluated in the pilot study. The adults who were evaluated were neurologically healthy, with average age of $29.70(S D=3.13)$ years old and average schooling of 11.35 years $(S D=2.34)$, equally distributed regarding gender. 


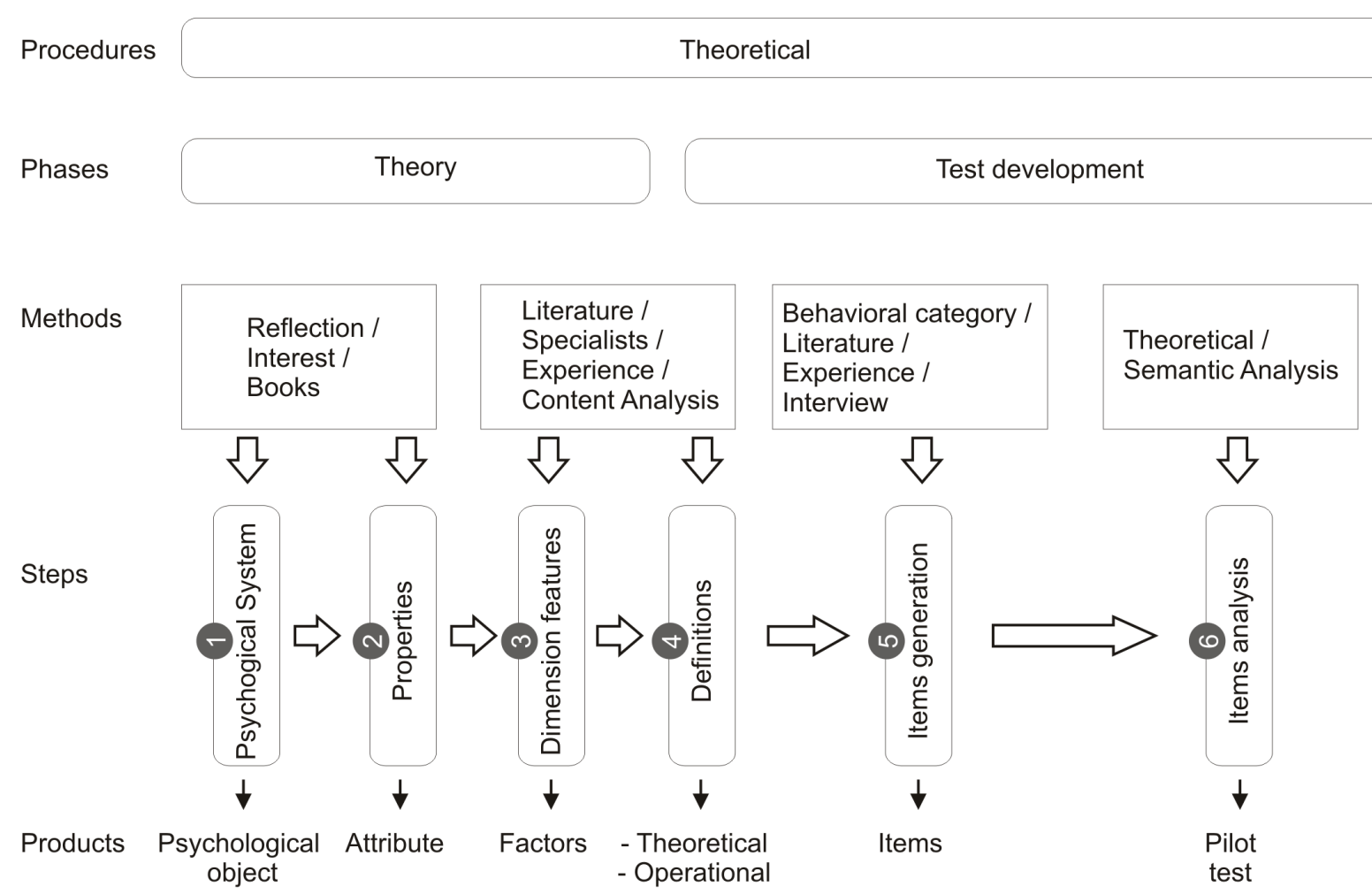

Figure 1 - Fluxogram of instrument construction. Adapted from Pasquali (1999).

\section{Instrument}

The Brief Neuropsychological Assessment Battery Neupsilin (Fonseca, Salles, \& Parente, in press) examines performance in the following neuropsychological processes: time and spatial orientation, sustained attention, visual perception (of size, visual fields and faces), arithmetic abilities (simple calculi), oral and written language, verbal memory (episodic, semantic, prospective and working memory) and visual memory (recognition), praxias (ideomotor, constructional and reflexive) and executive functions (problem solving and phonemic verbalfluency). Its final version resulted in short tasks with feasible resolution by neurologically healthy people. It can be classified as a brief neuropsychological assessment instrument because it demands a reduced application time (between 30 and 50 minutes). It assesses eight neuropsychological functions by means of 32 subtests, with a description of its application, stimuli and maximum scoring presented on Table 1.

Many of the tasks, such as reverse counting, provide a qualitative score as well, which can be indicated when direct counting and/or the presence of inhibition (to stop counting at number 30 ) occurs. In the verbal episodic memory task, the number of intrusions and perseverations are registered, along with primacy and recency effects. The copied writing and constructional motor abilities task may suggest hemineglect.

\section{Procedure}

The procedures for the instrument development and its content validity assessment will be presented in this section. Figure 1 displays the instrument construction fluxogram, adapted from Pasquali (1999).

The procedures described in Figure 1, although not entirely followed, guided the construction of Neupsilin. The seven steps of this process are specified below. The unique procedure that was not followed was the factor analysis, which will be studied with the normalization data.

1. Construction of a preliminary version of the instrument. The construction of the first version was founded on the clinical and research experience of three specialists (judges and instrument authors), as well as on literature review (Barbizet \& Duizabo, 1985; Daneman \& Carpenter, 1980; Lezak et al, 2004, MacDonald, Almor, Henderson, Kemple,r \& Andersen, 2001; Ostrosky-Solís et al, 1999; Peña-Casanova, 1987; Squire \& Kandel, 2003; Strauss et al, 2006) and on available national and international instruments, such as the Mini-Mental (Chaves \& Izquierdo, 1992), the Criteria of Positivity for Cognitive Deficit (Chaves \& Izquierdo, 1992), the NEUROPSI Evaluación Neuropsicológica Breve en Español (OstroskySolís et al., 1999) and the MT-86b Protocol (Nespoulous et al, 1986). This step was important to define attributes or properties of the system to be studied and to elaborate its conceptual and operational definitions.

2. Blind analysis of expert judges. This step was divided into two sub-steps: a) an analysis of the importance of including each subtest, by considering the construct to be assessed and the aim of the instrument; and b) an analysis of the pertinence of each item considering the evaluated construct. Seven judges with expertise in neuropsychology and two judges with expertise in psychological assessment participated in this analysis.

3. Instrument reformulation. The items which presented an agreement index inferior to .80 among the judges were substituted by new items suggested by the specialists and consensually chosen by the authors of the instrument. 
Table 1. Presentation of evaluated functions and components, items description and scoring of Neupsilin

\begin{tabular}{|c|c|c|}
\hline $\begin{array}{l}\text { Evaluated function and its } \\
\text { components }\end{array}$ & Administration (description) & $\begin{array}{l}\text { Maximum } \\
\text { Score }\end{array}$ \\
\hline
\end{tabular}

1.0 - Time and spatial orientation

\author{
1.1- Time \\ 1.2 - Space
}

2.0 - Attention (sustained)

2.1 - Reverse counting

2.2 - Digit sequence repetition

3.0 - Perception

\section{1 - Verification of similarity and mismatch between lines \\ 3.2 - Visual hemineglect \\ 3.3 - Face perception}

3.4 - Face recognition

4.0-Memory

\section{1 - Working memory}

4.1.A - Ascendent ordering of digits

4.1.B - Oral word span in sentences

4.2 - Verbal episodic-semantic memory

4.2.A - Immediate recall

4.2.B - Delayed recall

4.2.C - Recognition

4.3 - Long-term semantic memory

4.4 - Short-term visual memory

4.5 - Prospective memory
Day of the week and of the month, month and year (for example, Which day is today?)

Place, city, state and country (for example, Where are we now?)

Counting from 50 to 30 ; task execution time is measured

Seven-digit sequence repetition

Verification of length similarity or mismatch of six pairs of lines (for example, Are these lines the same size?)

Crossing out of all the lines distributed on a sheet

Assessment, as identical or different, of three pairs of pictures of faces, one in a frontal view and the other in profile faces initially presented
Repetition of 10 sets of digits, ranging from 2 to 6 digits in ascending order (for example, $7 ; 3$; answer $3 ; 7$ )

Repetition of sentences while the participant memorizes the final word of each sentence; at the end, recall in order of the final words of each set of presented sentences (two, three, four and five sentences) - for example, The cow bit a piece of com AND The girl sat on the bed; answer after the repetition of each sentence: com AND bed

Free recall of nine words said by the examiner (for example, arm, lion, fork, among others)

Free recall of the same nine words (after language subtests, around 15 minutes later)

Recognition of words from the target list containing 18 words (9 target words and 9 semantically related distractors, such as mouth, cat, spoon, etc)

Answer to two questions referring to general knowledge (for example, What are the colors of the Brazilian flag?)

Recognition of meaningless figure among a set of three stimuli

Execution, at testing ending, of name writing on a sheet of paper given at the beginning of the examination 
Table 1. (continuing)

\begin{tabular}{|c|c|c|}
\hline $\begin{array}{l}\text { Evaluated function and its } \\
\text { components }\end{array}$ & Administration (description) & $\begin{array}{l}\text { Maximum } \\
\text { Score }\end{array}$ \\
\hline 5.0 - Arithmetic abilities & $\begin{array}{l}\text { Four calculations resolution, one in each arithmetic basic } \\
\text { operation (for example, } 95-8 \text { ) }\end{array}$ & 8 \\
\hline \multicolumn{3}{|l|}{6.0 - Language } \\
\hline \multicolumn{3}{|l|}{6.1 - Oral language } \\
\hline 6.1.A - Naming & Naming of two objects and two figures & 4 \\
\hline 6.1.B - Repetition & $\begin{array}{l}\text { Repetition of eight real words (for example, snow) and two } \\
\text { non-words (for example, kabar) }\end{array}$ & 10 \\
\hline 6.1.C - Automatized language & $\begin{array}{l}\text { Counting from } 1 \text { to } 10 \text {; recall of all months of the year, in } \\
\text { order }\end{array}$ & 2 \\
\hline 6.1.D - Oral comprehension & $\begin{array}{l}\text { Pointing of the figure corresponding to the examiner's } \\
\text { reading of a word or sentence }\end{array}$ & 3 \\
\hline 6.1.E - Inferencial processing & Meaning explanation of a proverb and of two metaphors & 3 \\
\hline \multicolumn{3}{|l|}{6.2 - Written language } \\
\hline 6.2.A - Reading aloud & Reading of ten real words and two non-words & 12 \\
\hline 6.2.B - Written comprehension & $\begin{array}{l}\text { Indication of figures corresponding to the meaning of the } \\
\text { read words and sentences }\end{array}$ & 3 \\
\hline 6.2.C - Spontaneous writting & Writing of a sentente & 2 \\
\hline 6.2.D - Copied writting & $\begin{array}{l}\text { Copying of a sentence (for example, The physician works at } \\
\text { the hospital) }\end{array}$ & 2 \\
\hline 6.2.E - Dictated writting & writing of ten real words and two non-words & 12 \\
\hline \multicolumn{3}{|l|}{7.0 - Motor abilities } \\
\hline 7.1 - Ideomotor & $\begin{array}{l}\text { Execution of three simple gestures, according to the } \\
\text { examiner's verbal instruction }\end{array}$ & 3 \\
\hline 7.2 - Constructional & $\begin{array}{l}\text { Copy of three figures (square, flower and cube) and } \\
\text { drawing of a watch }\end{array}$ & 16 \\
\hline 7.3 Reflexive & $\begin{array}{l}\text { Repetition of a sequence of three gestures, according to a } \\
\text { given model }\end{array}$ & 3 \\
\hline \multicolumn{3}{|l|}{8.0 - Executive functions } \\
\hline 8.1 Problem solving & Answer to two questions involving abstract reasoning & 2 \\
\hline 8.2 Verbal fluency & $\begin{array}{l}\text { Verbalization, for one minute, of words beginning with the } \\
\text { letter F }\end{array}$ & $\begin{array}{l}\text { Number of } \\
\text { items }\end{array}$ \\
\hline
\end{tabular}

4. Semantic analysis of the items and brainstorming. For the semantic analysis of the item, three groups of four people were interviewed in the brainstorming modality. Items and instructions which imposed difficulties in comprehension were replaced and presented again to the participants. In the second version of the stimuli, generated after suggestions given by brainstorming participants, the items which did not impose comprehension problems were chosen.

5. Final analysis made by three specialist judges. After the reformulation proposed by the judges, the new items were analyzed by two specialist judges (who participated in the construction of the first version of the instrument) and the disagreements were submitted to a consensus achieved by a third judge, also a specialist.

6. Pilot study and final version of the instrument. The second version of the Neupsilin was analyzed by seven participants who also participated in stage 4, future test administrators. From the suggestions given, interpretation and administration norms were improved. Moreover, this version of the instrument was administered to 16 individuals as a pilot study, from which other adjustments in administration and scoring procedures were done, based on the difficulties reported by the examiners' group. The final version of the stimuli and of administration and 
scoring guides was approved by the authors.

7. Content validity. Content validity was developed by the raters' agreement analysis, including the same procedures described in phase 2 .

\section{Results}

Results will be presented in terms of criteria and modifications, which have been implemented in the Neupsilin development phases. In phase 1 , the construction of a preliminary version of the instrument, the psycholinguistic criteria that made up the final stimuli selection were familiarity, frequency, accessibility, conventionality, literality, regularity, lexical and syntactic extension, plausibility, clarity, prototypicality and level of abstraction. As an illustration, in the episodic-semantic memory task, nine words were chosen by controlling familiarity (words considered as being familiar by specialist judges in judgment scales), lexical extension (all disyllables) and semantic category (a priori, three sets of three words belonging to the same semantic field which included parts of the body [arm, finger and eye], kitchen utensils [plate, knife and fork], and animals [lion, snake and fish]). The manipulation of semantic categorization was aimed at evaluating the occurrence of intrusions for a qualitative analysis of mnemonic processing.

Regarding the familiarity criterion, the words selected for reading and writing assessment were chosen among those of the Portuguese version of the reading assessment protocol, elaborated for the Human Frontier Science Project (Parente, Hosogi, Delgado \& Lecours, 1992). This protocol was rigorously constructed based on models of written words processing and it is composed by words and non-words with varying degrees of extension, regularity, grammatical function, frequency and concreteness. Some non-words were selected from Salles and Parente (2002). Results from steps 2, 3, 4, 5 and 6 described in the procedures will be presented below. Table 2 illustrates the agreement indices among judges regarding the pertinence of each subtest.

Only two tasks were judged with an agreement index inferior to 0.80: attention - repetition of letter sequences - and face perception, justifying the following modifications. The first task was substituted by "attention - repetition of digit sequence," which is more traditional in neuropsychology and demands less formal education. The face perception task (recognition of famous faces) was modified (non-familiar faces) and subdivided into two other categories: face perception (judgment of equality or mismatch between two faces - one in a front view and the other in profile) and face recognition. This change was implemented due to the criticism made by some of the judges about the great demand upon semantic and visual memory in the first version.

Regarding the pertinence analysis of each item in relation to the assessed construct, only one item of the subtest time and spatial orientation had an agreement index inferior to .80 (.78). After the analyses of quantitative and qualitative findings, some modifications were implemented, which are

Table 2. Inter-raters' agreement indices on the pertinence of each subtest

\begin{tabular}{lc}
\hline Cognitive processes & Agreement index \\
\hline Visual and time orientation & 1.0 \\
Attention - reverse counting & .89 \\
Attention - sequence of letters repetition & .78 \\
Perception - similarities and differences verification & .89 \\
Perception - visual unilateral neglect & .87 \\
Face perception & .67 \\
Working memory - ascendant order of digits & 1.0 \\
Working memory - auditory word span in sentences & .89 \\
Verbal memory - recall (immediate and delayed) & 1.0 \\
Verbal memory - recognition & 1.0 \\
Visual memory - recognition & 1.0 \\
Oral language - naming & 1.0 \\
Oral language - repetition & 1.0 \\
Oral language - automatized language & .89 \\
Oral language - comprehension & 1.0 \\
Oral language - inference processing & 1.0 \\
Written language - reading & .89 \\
Written language - written comprehension & .89 \\
Written language - spontaneous writing & 1.0 \\
Written language - copied writting & .89 \\
Written language - dictated writting & .89 \\
Arithmetic abilities & .87 \\
Motor abilities - ideomotor & 1.0 \\
Motor abilities - constructional & .89 \\
Motor abilities - reflexive & .87 \\
Verbal reasoning & 1.0 \\
Executive functions - planning & .89 \\
\hline & \\
\hline
\end{tabular}


Table 3. Suggestions given by raters, consensually accepted by the authors, and executed changes

\begin{tabular}{|c|c|}
\hline $\begin{array}{l}\text { Cognitive } \\
\text { processes }\end{array}$ & Executed changes \\
\hline $\begin{array}{l}\text { Time and space } \\
\text { orientation }\end{array}$ & $\begin{array}{l}\text { The order of the items was changed, starting with the one which represents } \\
\text { lower quantity and is more familiar. } \\
\text { The autopsychic item "age" was removed. }\end{array}$ \\
\hline Attention & $\begin{array}{l}\text { The reverse counting task was reduced in extension and, as a consequence, in } \\
\text { complexity. } \\
\text { The task "Repetition of a letter sequence" (V, T, E, L, F, Q) was substituted by a } \\
\text { "Digit span" task ( } 4,9,2 \text { etc). }\end{array}$ \\
\hline Perception & $\begin{array}{l}\text { The original figure copy (square, flower, cube, stairs, and bicycle) had a reduc- } \\
\text { tion in the number of items. Only the first three items remained in the task, but in } \\
\text { another one, for the assessment of constructional motor functions. } \\
\text { Subdivision in two tasks: face perception and face recognition. }\end{array}$ \\
\hline $\begin{array}{l}\text { Working } \\
\text { memory }\end{array}$ & $\begin{array}{l}\text { Task name of Word span was modified to auditory word span in sentences and } \\
\text { the largest sentence sequence was omitted: The singer left the room; The mother } \\
\text { cooked beans; The doctor played cards; The actress painted the table; The nun } \\
\text { ran in the field; The man picked the apple. }\end{array}$ \\
\hline $\begin{array}{l}\text { Verbal } \\
\text { episodic- } \\
\text { semantic } \\
\text { memory }\end{array}$ & $\begin{array}{l}\text { Words from the recognition list were randomly regrouped. } \\
\text { The semantic memory task was included. }\end{array}$ \\
\hline Visual memory & The stimuli-figures were edited to enlarge line thickness. \\
\hline Oral language & In the repetition task, the stimulus "apor" was replaced by "prina". \\
\hline Written & In the reading aloud task, the non-word "munro" was replaced by "cusbe" \\
\hline language & In the dictated written task, the stimulus "vesta" was replaced by "varpa". \\
\hline Motor abilities & The final gesture was substituted by a less complex one. \\
\hline $\begin{array}{l}\text { Verbal } \\
\text { reasoning }\end{array}$ & This task was substituted by the problem solving task. \\
\hline $\begin{array}{l}\text { Executive } \\
\text { function - } \\
\text { planning }\end{array}$ & This task was replaced by the executive function task - verbal fluency. \\
\hline
\end{tabular}

displayed on Table 3. The nine judges (second group) were asked to give suggestions regarding the items considered to be pertinent to the examined cognitive process or subcomponents. These suggestions were grouped in a blind judgment task by two judges (from the first group), whose disagreements were submitted to a consensus achieved by a third specialist judge (also from the first group of judges). In relation to content validity, the final version of the instrument (instruction and stimuli) was again submitted to the nine specialist judges, resulting in agreement indices superior to .80 .

\section{Discussion}

The construction of the Brief Neuropsychological Assessment Battery Neupsilin was founded on a high level of theoretical and methodological rigor in what concerns both psychometric and neuropsycholinguistic underlying postulations. The careful development of this neuropsychological assessment tool was an initial step towards reducing the number of national standardized resources for the evaluation of cognitive processes.

After the accomplishment of theoretical and experimental procedures, evidence of reliability and of criterion and construct validity was searched for. Moreover, all the analytic procedures which guarantee the instrument's normalization for education and age were adopted. The studies developed were the following: (1) normalization (from 13 to 90 years old);
(2) reliability evidence (test-retest and internal consistency), (3) validity evidence (correlation with other instruments, comparison of criterion-groups of schooling and right brain damage). Such data can be consulted in the guide of the instrument (Fonseca, Salles \& Parente, in press).

Among Neupsilin's advantages, the most notable is its brief administration, assessing all neuropsychological functions in one single session, in addition to the bases on which the items were constructed (neuropsychology, psychometrics, psycholinguistics, cognitive experimental psychology). Additionally, the instrument allows for advancing from a screening assessment to a measurement, which provides a both quantitative and qualitative profile of preserved abilities and impaired functions. Another advantage is the inclusion of tasks of inference processing evaluation, generally neglected even in language assessment batteries, which privilege structural aspects in detriment of functional ones. The task of preserved prospective memory assessment can also be considered a distinguishing aspect of the instrument, since it is usually not included even in memory assessment batteries.

In addition to Neupsilin's advantages, it is important to mention the limitations of the brief battery developed; for instance, the reduced number of items per task result in less representativeness of the several components of attention (sustained attention only), arithmetic abilities (simple operations), executive functions (only simple verbal problem solving and verbal fluency with phonemic-orthographic 
restriction). While developing any assessment instrument some decisions need to be taken, considering the aims of the test and its cost-benefit relationship. In the case of the Neupsilin, application time - in one session - was prioritized, as well as a more detailed investigation of memory and language, functions which are complex and with a high prevalence of deficits. Still, implicit mnemonic components and linguistic processing at the discourse level were not covered. Such limitations, inherent to the development of brief or screening instruments, are frequently mentioned in the literature (for example, the FAB - a Frontal Assessment Battery - Dubois, Slachevsky, Litvan, \& Pillon, 2000; Batterie de dépistage de la négligence spatiale - Rousseaux et al., 2001; NEUROPSI - Evaluación Neuropsicológica Breve en Español, OstroskySolís et al., 1999; Expanded Trail Making Test, Stanczak, Lynch, McNeil, \& Brown, 1998).

Neupsilin should not be adopted as the only instrument in a neuropsychological assessment process. Such a process goes far beyond the limits of the use of standardized tests (Fonseca, Salles, \& Parente, 2007). Moreover, in the context of test use, whenever any deficit is identified in a determined function, the investigation moves further and more deeply by means of the administration of other specific neuropsychological tools. Regarding qualitative data, the Neupsilin provides evidence on the use of cognitive strategies (analysis of error types and time of execution), allowing some rehabilitation techniques planning and, as an advantage, it may permit the differentiation between impairments caused by lesions in left and right brain hemispheres, mainly of those related to communicative, mnemonic and perceptive processing, since it encompasses the assessment of both structural and functional linguistic processing, as well as hemineglect research. Besides, it also aims to provide a neuropsychological profile of the neurologically healthy population, in several phases of human development, from adolescence to old age.

Regarding future studies, some suggestions can be mentioned. It is still necessary to verify performance regarding age, education, gender and type of school variables. In addition, sensitivity and specificity for different clinical groups and profiles and norms for neurological and/ or specific psychopathological populations are necessary. Studies of rehabilitation efficiency evidence are also crucial. These investigations will probably contribute to the developing of evidence-based neuropsychology.

\section{References}

Almeida, O. P. (1998). Mini Exame do Estado Mental e o Diagnóstico de Demência no Brasil. Arquivos de Neuropsiquiatria, 56(3), 605-612.

Barbizet, J. \& Duizabo, P. (1985). Manual de neuropsicologia. Porto Alegre: Artes Médicas.

Beato, R. G., Nitrini, R., Formigoni, A. P., \& Caramelli, P. (2007). Brazilian version of frontal assessment battery (FAB): preliminary data on administration to healthy elderly. Dementia \& Neuropsychologia, 1 (1), 59-65.

Bertolucci, P.H.F., Brucki, S.M.D., Campacci, S.R., \& Juliano, Y. (1994). O Mini-exame do Estado mental em uma população geral - impacto da escolaridade. Arquivos de Neuropsiquiatria, 52(1), 1-7.

Brookshire, R.H. (2003). Intruduction to Neurogenic Communication Disorders. Missouri: Mosby.

Camozzato, A.; Chaves, M L F. (2002). Schizophrenia in males of cognitive performance: discriminative and diagnostic values. Revista de Saúde Pública, 36(6), 743-748.

Capitani, E.(1997). Normative data and neuropsychological assessment. Common problems in clinical practice and research. Neuropsychological Rehabilitation, 7(4), 295-309.
Chaves, M. L. \& Izquierdo, I. (1992). Differential diagnosis between dementia and depression: a study of efficiency increment. Acta Neurologica Scandinavia, 11, 412-429.

Daneman, M. \& Carpenter, P. A. (1980). Individual differences in working memory and reading. Journal of Verbal Learning and Verbal Behavior, 19, 450-466.

Dubois, B., Slachovsky, A., Litvan, I., \& Pillon, B.(2000). A frontal assessment battery at bedside. Neurology, 55, 1621-1626.

Folstein, M. F., Folstein, S. E., \& McHugh, P. R. (1975). Mini-mental state. Journal of Psychiatry Resources, 12, 189-198.

Fonseca, R.P., Salles, J. F., \& Parente, M.A.M.P. (in press). Instrumento de Avaliação Neuropsicológica Breve Neupsilin. São Paulo: Vetor Editora.

Fonseca, R.P., Salles, J. F., \& Parente, M.A.M.P. (2007). Ferramenta útil na pesquisa e clínica de neuropsicologia: "Um Compêndio de Testes Neuropsicológicos." Interamerican Journal of Psychology, 41(3), 403-405.

Gernsbacher, M.A. (1994). The handbook of psycholinguistics. San Diego, CA: Academic Press.

Geissinger, K.F. (1994). Cross-cultural normative assessment: translation and adaptation issues influencing the normative interpretation of assessment instruments. Psychological Assessment, 6(4), 304-312.

Geissinger, K.F. (1998). Psychometric issues in test interpretation. In Sandoval, J., Frisby, C.L., geisinger, K.F., Scheuneman, J.D., \& Grenier, J.R. (Eds.). Test interpretation and diversity (pp. 17-30). Washington, DC: American Psychological Association.

Guillevic, C. \& Vautier, S. (2005). Diagnostic et tests psychologiques (2e éd.). Paris: Armand Colin.

Harley, T. (2001). The psychology of language. New York: Psychology Press.

Lezak, M. D., Howieson, D. B., \& Loring, D. W. (2004). Neuropsychological Assessment. New York: Oxford University Press.

MacDonald, M., Almor, A., Henderson, V., Kempler, D., \& Andersen, E. (2001). Assessing working memory and language comprehension in Alzheimer's Disease. Brain and Language, 78, 17-42.

Nespoulous, J.L., Joanette, Y., \& Lecours, A.R. (1986). Protocole Montréal-Toulouse d'examen linguistique de l'aphasie (mt-86). Isbergues: Ortho Edition.

Ostrosky-Solís, F., Ardila, A., \& Rosselli, M. (1999). NEUROPSI: a brief neuropsychological test battery in Spanish with norms by age and educational level. Journal of the International Neuropsychological Society, 5, 413-433.

Parente, M.A. M.P. \& Salles, J. F. (2007). Processamento da linguagem em tarefas de memória. In: Memória: Cognição e Comportamento (pp. 231-255). Ed.São Paulo: Casa do Psicólogo.

Parente, M.A.M.P.; Hosogi, M.L., Delgado, A.P., \& Lecours, A.R. (1992). Reading Protocol for the HFSP Project. São Paulo (non-published manuscript).

Pasquali, L. (1999). Escalas psicométricas. In: Pasquali, L. (ed.). Instrumentos psicológicos: manual prático de elaboração, (pp. 105126). Brasília: LabPAM

Pasquali, L. (2003). Psicometria: Teoria dos testes na psicologia e na educação. Petrópolis: Vozes.

Peña-Casanova, J. P. (1987). VII Congreso nacional de neurología. Barcelona: Sociedad Española de Neurología.

Reis, A. \& Castro-Caldas, A. (1997). Illiteracy: a cause for biased cognitive development. Journal of the International Neuropsychological Society, 3, 444-450.

Rey, A. (1958). L'examen clinique en psychologie. Paris: Presse Universitaire de France.

Rousseaux, M., Beis, J.M., Pradat-Diehl, P., Martin, Y., Bartolomeo, P., et al. (2001). Présentation d une batterie de dípistage de la négligence spatiale. Normes et effets de l'âge, du niveau d'éducation, du sexe, de la main et de la latéralité. Revue Neurologique(Paris), 11, 13851400 .

Salles, J. F. \& Parente, M. A. P. P. (2002). Relação entre os processos cognitivos envolvidos na leitura de palavras e as habilidades de consciência fonológica em escolares. Pró-Fono Revista de Atualização Cientifica, 14 (2), 141-286.

Salles, J. F. \& Parente, M.A. M. P. (2007). Avaliação da leitura e escrita de palavras em crianças de $2^{\mathrm{a}}$ série: abordagem neuropsicológica cognitiva. Psicologia: Reflexão e Crítica, 20(2), 218-226.

Sevilla, J. G. (1997). Psicología de la Atención. Madrid: Síntesis.

Squire, L. R., Kandel, E. R. (2003). Memória: da mente às moléculas. Porto Alegre: Artes Médicas.

Stanczak, D.E., Lynch, M.D., McNeil, C.K., \& Brown, B.(1998). The expanded trail making test: rationale, development, and psychometric properties. Archives of Clinical Neuropsychology, 13(5), 473-487.

Strauss, E., Sherman, E.M.S., \& Spreen, O. (2006). A Compendium of Neuropsychological Tests: Administration, Norms and Commentary $\left(3^{\text {rd }}\right.$ ed.). New York: Oxford University Press.

Urbina, S. (2004). Essentials of psychological testing. Hoboken. New Jersey: John Wiley \& Sons.

Willmes, K. (1998). Methodological and Statistical Considerations in Cognitive neurolinguistics. In: B. Stemmer \& H.A. Whitaker (Orgs.). Handbook of Neurolinguistics (pp. 75-70). USA: Academic Press.

Wood, G. M. O., Carvalho, M. R. S., Rothe-Neves, R., \& Haase, V. G. (2001). Validação da bateria de avaliação da memória de Trabalho (BAMT-UFMG). Psicologia: Reflexão e Crítica, 14 (2), 325-341. 